\title{
Slip system determination by rolling texture measurements around the strength peak temperature in a $\mathrm{Fe}_{3} \mathrm{Al}$-based alloy
}

\author{
S. Kobayashi ${ }^{\text {a,* }}$, S. Zaefferer ${ }^{\text {a }}$, A. Schneider ${ }^{\text {b }}$, D. Raabe ${ }^{\text {a }}$, G. Frommeyer ${ }^{\text {b }}$ \\ ${ }^{a}$ Department of Microstructure Physics and Metal Forming, Max Planck Institute for Iron Research, Max-Planck-Str. 1, D-40237 Düsseldorf, Germany \\ ${ }^{\mathrm{b}}$ Department of Materials Technology, Max Planck Institute for Iron Research, Max-Planck-Str. 1, D-40237 Düsseldorf, Germany
}

Received 25 August 2003; received in revised form 30 January 2004

\begin{abstract}
Texture measurements were carried out on a Fe-26Al-5Cr alloy that was deformed by warm rolling at temperatures above and below the stress anomaly temperature in order to obtain information about a possible change of slip systems around that temperature. Special attention was paid to the initial microstructure, temperature during rolling and recrystallisation problems. Textures were determined by automatic crystal orientation mapping (ACOM) using electron backscatter diffraction (EBSD), which allows separation of measurement data from recrystallised and unrecrystallised fractions in the microstructure. A clear difference in texture evolution appears above and below the stress anomaly temperature; the most preferred orientations after rolling at 600 and $400^{\circ} \mathrm{C}$ are $\sim\{557\}\langle 110\rangle$ and $\sim\{111\}\langle 211\rangle$, respectively. This result suggests that the shear fraction of the active $\left\{\begin{array}{lll}1 & 12\end{array}\right\}\left\langle\begin{array}{lll}1 & 1 & 1\rangle\end{array}\right.$ slip systems increases with respect to that of the $\{110\}\langle 111\rangle$ slip systems with increasing temperature around the stress anomaly temperature.
\end{abstract}

(C) 2004 Elsevier B.V. All rights reserved.

Keywords: $\mathrm{Fe}_{3} \mathrm{Al}$ intermetallic; Stress anomaly; Rolling texture; ACOM; EBSD

\section{Introduction}

$\mathrm{Fe}_{3} \mathrm{Al}$-based intermetallic alloys with $\mathrm{D} 0_{3} / \mathrm{B} 2$ structure show a yield stress anomaly at an intermediate temperature $[1,2]$. For many years a great deal of efforts has been devoted to explaining this phenomenon, and several theories were proposed and reviewed [1]. Early researchers considered that the stress anomaly was related to the occurrence of a structural change from $\mathrm{D}_{3}$ to $\mathrm{B} 2$ near the anomaly temperature. In contrast, nowadays the kind of slip systems activated during deformation is thought to be a key for this phenomenon, at least on this $\mathrm{Fe}_{3} \mathrm{Al}$ (not $\mathrm{FeAl}$ ) alloy. Recently, the stress anomaly temperatures were shown not to correspond directly with the $\mathrm{D}_{3} / \mathrm{B} 2$ transition temperatures in several alloys [3].

On the basis of many TEM studies, it was proposed that with increasing temperature near the stress anomaly temperature the active slip systems change from $\left\{\begin{array}{lllll}1 & 1 & 0\end{array}\right\}\left\langle\begin{array}{llll}1 & 1 & 1\end{array}\right\rangle$ superlattice dislocations to $\left\{\begin{array}{lll}1 & 1 & 0\end{array}\right\}\langle 100\rangle$ and/or $\left\{\begin{array}{lll}1 & 0 & 0\end{array}\right\}\langle 100\rangle$

\footnotetext{
* Corresponding author. Tel.: +49 2116792 321; fax: +492116792333.

E-mail address: kobayashi@mpie.de (S. Kobayashi).
}

perfect dislocations. A serious problem with investigation of slip systems by TEM, however, is the possible decomposition and/or formation of dislocations during cooling and the loss of dislocations during sample preparation. In fact, it was confirmed by later TEM investigations on samples prepared with different cooling rates after hot deformation that the dislocations with $\langle 100\rangle$ Burgers vector were formed during cooling [4]. Therefore, a conventional TEM study is not suitable to determine the slip systems activated at high temperatures in these alloys.

An alternative method to study the activation of slip systems during deformation is the investigation of the warm rolling texture evolution in dependence of the deformation temperature. Preliminary examinations carried out by Raabe [5] and Kad and Horton [4] have shown that the slip systems activated above the strength-peak temperature still have a

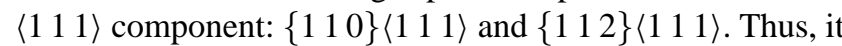
is interesting to know if any change in the active slip systems can be determined from rolling texture experiments above and below the stress anomaly temperature.

In the present study, texture measurements were carried out on a $\mathrm{Fe}_{3} \mathrm{Al}$-based alloy that was deformed by rolling at precisely controlled temperatures above and below the peak 
temperature. In order to get the precise rolling texture evolution from the experiment, close attention was paid to the following points. The first point is preparation of an initial fine-grained structure with, at best, a random orientation distribution because the texture study relies on statistics. The second is the control of the rolling temperature. The last point is the consideration of recrystallisation that may occur during and/or after hot rolling with large deformation, as suggested by Morris and Morris [1].

\section{Experimental procedure}

A Fe-26Al-5Cr alloy was prepared, which shows a yield stress anomaly peak at around $550-600^{\circ} \mathrm{C}$. Since the as-cast microstructure has very large grains with a size of more than $1 \mathrm{~mm}$, this alloy was hot rolled and recrystallised to get a homogeneous and fine-grained structure in order to obtain good statistical results of the texture measurements. The rolled and heat-treated specimens (hereafter referred to as the 'starting material') were cut into blocks of $50 \mathrm{~mm} \times$ $100 \mathrm{~mm} \times 5 \mathrm{~mm}(\mathrm{TD} \times \mathrm{RD} \times \mathrm{ND})$.

The blocks were subsequently warm/hot rolled at $400{ }^{\circ} \mathrm{C}$, below the stress anomaly, at $600^{\circ} \mathrm{C}$ near the peak and $700{ }^{\circ} \mathrm{C}$ above the peak. The rolling was performed on a laboratory rolling mill with $10-15 \%$ reduction per pass. After several passes, the samples were oil quenched, cut, re-heated and rolled again. This procedure was repeated up to a reduction of about $70 \%$. The temperature during the rolling was measured by a thermocouple that was embedded in the edge of the specimen. The decrease in temperature during rolling was less than $50^{\circ} \mathrm{C}$.

Texture measurements were done by automatic crystal orientation mapping (ACOM) which is based on the automatic analysis of electron backscattered diffraction (EBSD) patterns in the SEM. For all specimens, the texture was determined on a plane parallel to the rolling plane in the center layer $(s=0)$ of the specimens. The samples were prepared for measurement by mechanical grinding, polishing and electropolishing. The measured sample area had a size of approximately $15 \mathrm{~mm} \times 5 \mathrm{~mm}$ and was scanned with a step size of $20 \mu \mathrm{m}$.

\section{Results and discussion}

\subsection{Initial microstructure and texture of the starting material}

Complete recrystallisation could not be achieved even after $82 \%$ reduction at $800^{\circ} \mathrm{C}$ followed by various heat treatment conditions, thus the initial microstructure is unfortunately quite heterogeneous. Fig. 1 shows an EBSD misorientation map of the starting material, which is rolled at $800{ }^{\circ} \mathrm{C}$ to a reduction of $82 \%$ followed by a heat treatment at $1000{ }^{\circ} \mathrm{C}$ for $20 \mathrm{~h}$. In this picture, low angle grain boundaries of about $1-15^{\circ}$, and grain boundaries with more than $15^{\circ}$ misorientation are shown as thin and thick lines, respectively. This specimen still contains about 50\% unrecrystallised grains, which are elongated and show high internal misorientations. The other $50 \%$ consist of relatively fine recrystallised grains of approximately $200 \mu \mathrm{m}$ in average diameter, which do not show any detectable misorientations in their interior.

Fig. 2 shows the textures represented by $\varphi_{2}=45^{\circ}$ sections of the orientation distribution function (ODF) calculated from the EBSD measurements on the normal plane in the recrystallised regions (a) and unrecrystallised regions (b). The recrystallised area shows quite a weak texture although the $\gamma$-fibre $\left(\begin{array}{lll}1 & 1 & 1\end{array}\right)\langle u v w\rangle$ is visible. On the other

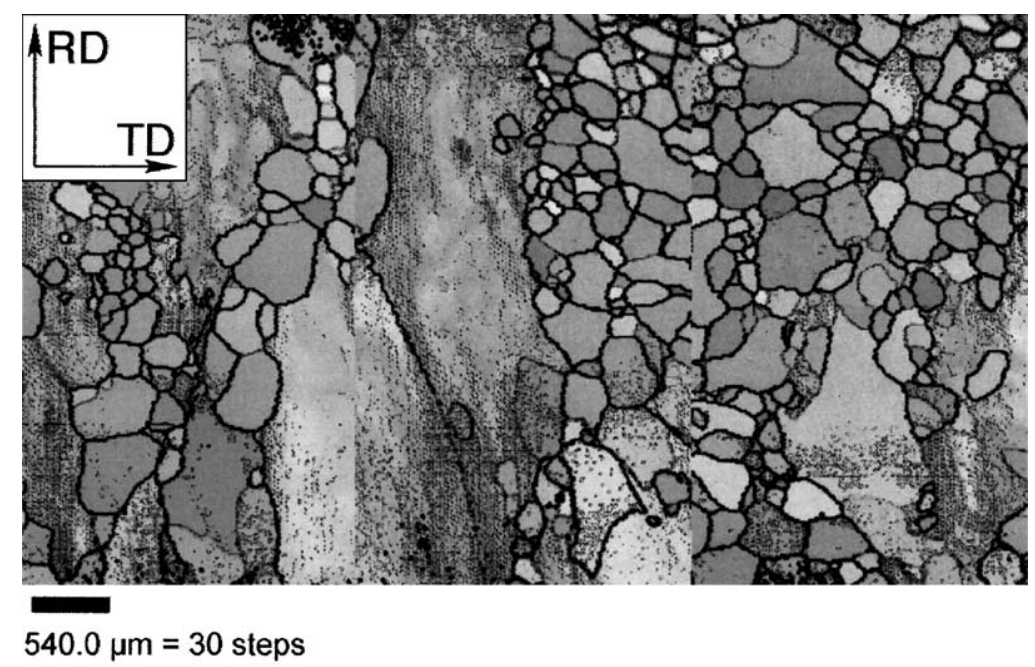

Fig. 1. EBSD misorientation map of the $\mathrm{Fe}-26 \mathrm{Al}-5 \mathrm{Cr}$ alloy, rolled at $800^{\circ} \mathrm{C}$ to a reduction of $82 \%$ and heat-treated at $1000{ }^{\circ} \mathrm{C}$ for $20 \mathrm{~h}$ (starting material), showing recrystallised and unrecrystallised areas. Thin and thick lines correspond to boundaries with misorientations of $1-15^{\circ}$ and more than $15^{\circ}$, respectively. Step size is $20 \mu \mathrm{m}$. 


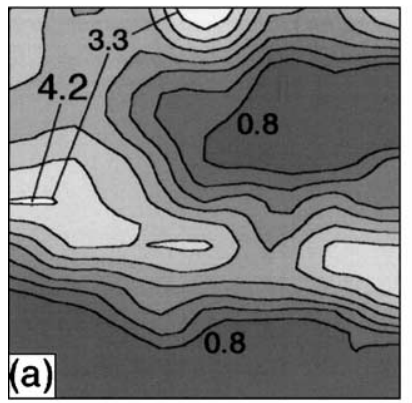

$\varphi_{1} \rightarrow$

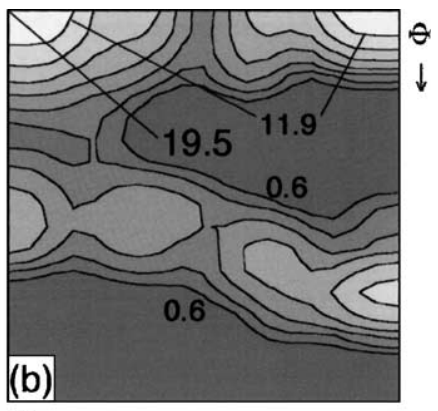

$\varphi_{1} \rightarrow$

Fig. 2. $\varphi_{2}=45^{\circ}$ section of the orientation distribution function (ODF) of the starting specimen from the recrystallised area (a) and the unrecrystallised area (b), represented by equal-density lines. The recrystallised area shows a weak texture with maximum density of 4.2 , on the other hand, the unrecrystallised area shows strong rotated cube with maximum density of 19.5. The densities were calculated from the separated volume fractions. See Fig. 4 for indication of typical orientations in these graphs.

hand, the unrecrystallised area shows strong texture components: especially the rotated cube component $\left(\begin{array}{lll}0 & 0 & 1\end{array}\right)\left\langle\begin{array}{lll}1 & 1 & 0\end{array}\right)$ and orientations on the $\gamma$-fibre. The strong resistance of the rotated cube component against recrystallisation was also reported in a previous work [6] and is related to the fact that the rotated cube component does not form any orientational break-up during rolling [7]. Other components, in contrast, develop strong orientation gradients or subgrain structures during rolling.

The very strong texture difference between the recrystallised and unrecrystallised areas in the starting material and their different evolution during rolling points out the need for a texture measurement technique that is able to distinguish between both areas. This is not possible with X-ray diffraction techniques, which integrate over the whole volume. In contrast, ACOM is an ideal method since it determines microstructure and spatially resolved texture at the same time. In the current work the separation of recrystallised and unrecrystallised volume fractions in the starting material has been performed on the basis of their different grain sizes. During warm rolling the grains corresponding to the originally recrystallised grains were identified by their grain size and aspect ratio which developed in accordance with the degree of rolling.

\subsection{Recrystallisation during rolling experiments}

During rolling at 400 and $600{ }^{\circ} \mathrm{C}$, recrystallisation did not occur even at the highest deformation degree. On the other hand, at $700{ }^{\circ} \mathrm{C}$ dynamic and/or static recrystallisation starts to occur at a reduction of $50 \%$, as can be seen in Fig. 3 which shows small equiaxed recrystallised grains in between the larger elongated crystals. This result indicates that texture measurements performed by X-ray diffraction on samples rolled at higher temperatures [5] probably also contained data from recrystallised microstructure components and are therefore not significant for the investigation of deforma-

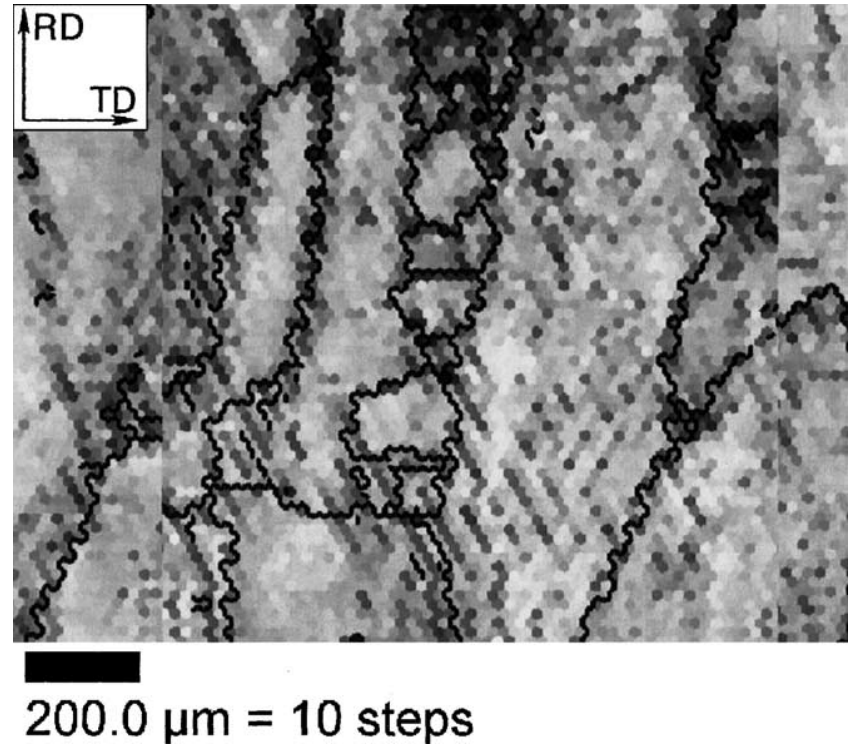

Fig. 3. EBSD misorientation map of the specimen rolled at $700{ }^{\circ} \mathrm{C}$ to a reduction of $50 \%$, showing the occurrence of recrystallisation during rolling. Black lines correspond to boundaries with misorientations of more than $15^{\circ}$

tion mechanisms. This once again points out the necessity for a texture measurement technique that is able to discriminate between deformed and recrystallised microstructure fractions as the here chosen EBSD technique does.

\subsection{Texture evolution during rolling experiments}

The orientation change of the grains during rolling was determined only for the recrystallised grain fraction in the starting material. Fig. 4 shows the rolling textures of some rolled samples, represented by the $\varphi_{2}=45^{\circ}$ section of the ODF together with a scheme of this section that displays the main texture fibres and components visible. The $\alpha$-fibre and $\gamma$-fibre which appear, respectively, along the line of $\varphi_{1}$ $=0^{\circ}$ and the line of $\Phi=55^{\circ}$ in this section are often used to characterize the texture of bcc materials. However, it is known that particularly the $\gamma$-fibre is only an approximation of the true position of the preferred orientation fibre and that the texture is more precisely characterized using the skeleton line which follows the position of the maximum along the fibre [8]. In particular, the position of the skeleton line should depend on the amount of shear and on the kind of the active slip systems. Therefore, in this work the position and intensity of the maximum on the skeleton lines was determined. The orientation density of the maximum position and their Euler angles of $\Phi$ and $\varphi_{1}$ (at $\varphi_{2}=45^{\circ}$ and $\varphi_{1}<30^{\circ}$ for reasons of symmetry) were plotted as a function of deformation degree in Fig. 5a-c, respectively. The maximum density increases with deformation up to a value of 15 at $70 \%$ of deformation. The rate of intensity increase in dependence of reduction is nearly independent of rolling temperature, except for the $700{ }^{\circ} \mathrm{C}$ case for which the 

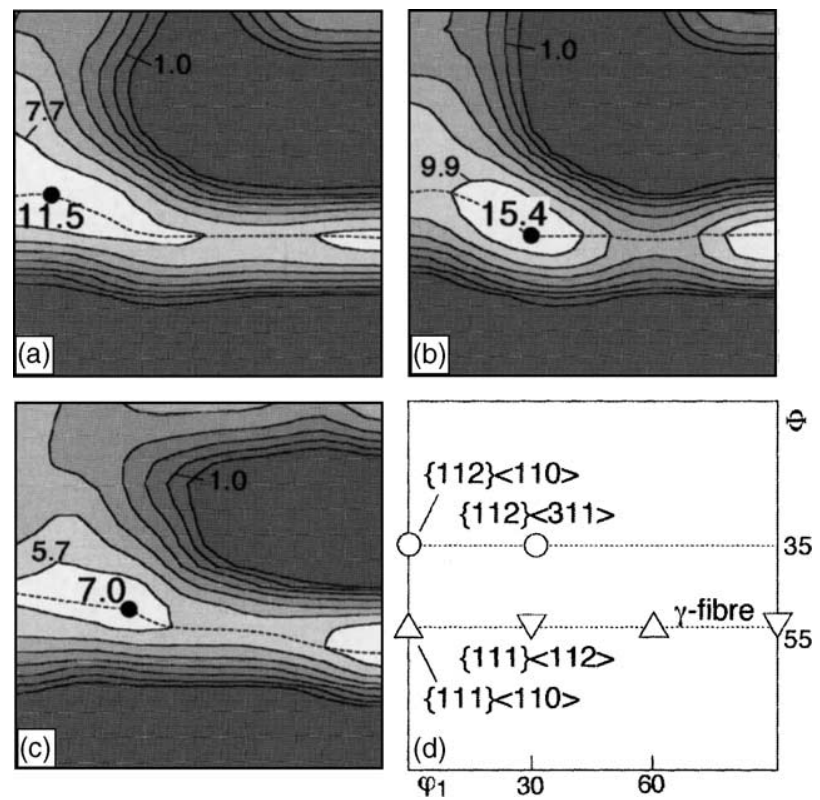

Fig. 4. $\varphi_{2}=45^{\circ}$ sections in the ODF of the rolled samples represented by equal-density lines, together with the most preferred orientations and skeleton lines represented by points and broken lines, respectively: (a) $400{ }^{\circ} \mathrm{C} / 65 \%$, (b) $600{ }^{\circ} \mathrm{C} / 73 \%$, (c) $700^{\circ} \mathrm{C} / 34 \%$, (d) schematic representation of the main texture components.

maximum orientation density stays constant after $40 \%$ reduction. This deviation from the behaviour of the specimens rolled at the other temperatures is due to the onset of recrystallisation and these data cannot be used for the further analysis. The most preferred orientation after deformation shows a clear dependence on the rolling temperature. At $400^{\circ} \mathrm{C}$, the orientation almost remains at $\Phi=45^{\circ}$ and $\varphi_{1}=0-10^{\circ}$ $(\sim\{557\}\langle 110\rangle)$ during the entire rolling process. Whereas at higher temperatures the orientation moves toward the position of $\Phi=55^{\circ}$ and $\varphi_{1}=30^{\circ}(\sim\{111\}\langle 211\rangle)$.

The clear change in the texture evolution between rolling temperatures of 400 and $600{ }^{\circ} \mathrm{C}$ suggests a change in the fraction of the slip systems activated between these temperatures. As a first approach to understand the change, a simple Sachs model was applied. This model which assumes that only the slip system with the highest Schmid factor is activated, was used although this is, of course, a rough approximation of the real deformation behaviour. The corresponding crystal rotation is such that the slip plane normal moves towards the axis of compression stress while the slip direction moves towards the tensile axis. Considering, as a first approximation, that the stress state in rolling can be represented, after subtraction of hydrostatic stress components, by compression along the normal direction and tension along the rolling direction. In this case the alternating activity of two, respectively three glide systems leads to the formation of a $\left\langle\begin{array}{llll}1 & 1 & 2\end{array}\right\rangle$ normal direction, if only $\left\{\begin{array}{llll}1 & 1 & 0\end{array}\right\}\left\langle\begin{array}{llll}1 & 1 & 1\end{array}\right\rangle$ slip systems are active, or to a $\langle 111\rangle$ normal direction, if only $\{112\}\langle 111\rangle$ slip systems are active. According to [9], where the same assumption concerning the stress state of
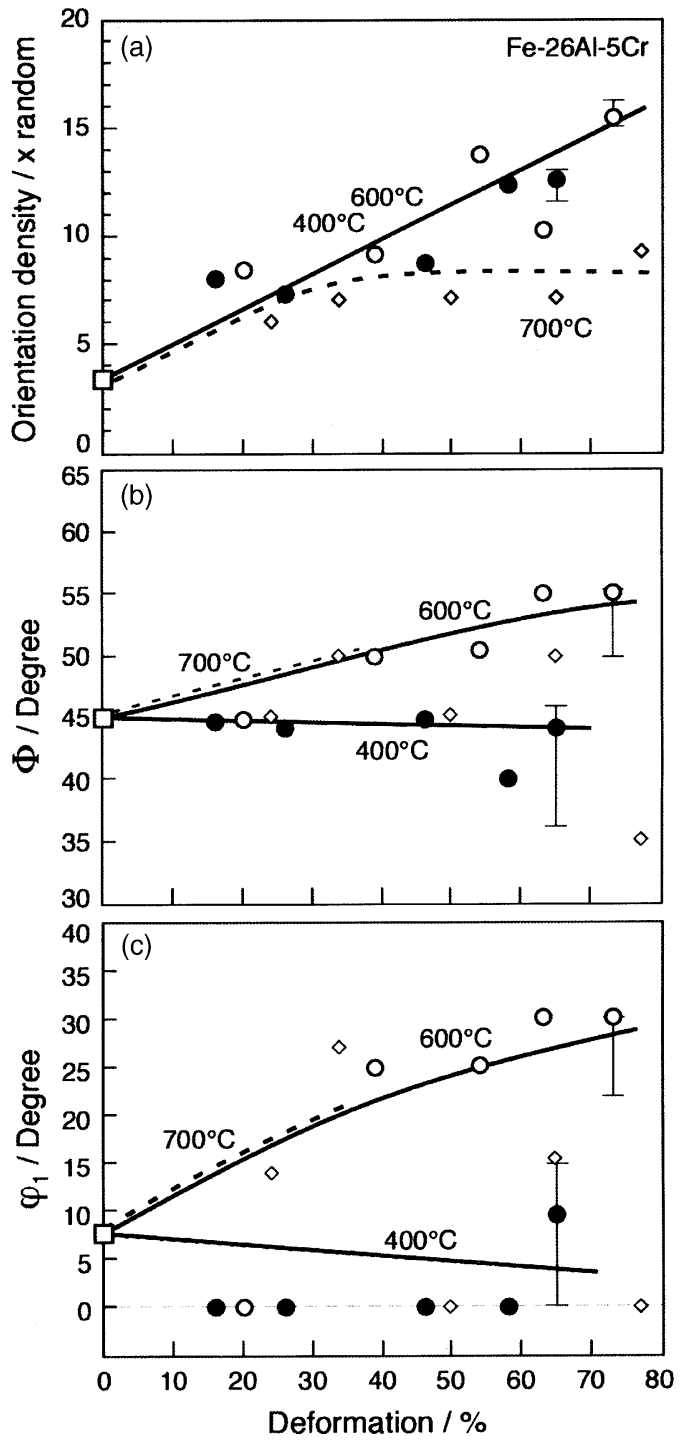

Fig. 5. Change of orientation density and position in Euler space of the most preferred orientation as a function of deformation degree: (a) orientation density, (b) $\Phi$, (c) $\varphi_{1}$. Solid circles, open circles and diamonds correspond to 400,600 and $700^{\circ} \mathrm{C}$, respectively. The most preferred orientation shifts to $\left(\varphi_{1} \Phi \varphi_{2}\right)=(305545)$ at $600^{\circ} \mathrm{C}$, while it remains at (0-10 45 45) at $400^{\circ} \mathrm{C}$. Trend lines are not shown for values of samples rolled more than $50 \%$ at $700^{\circ} \mathrm{C}$ in (b) and (c) because recrystallisation occurred.

rolling was made, the most preferred orientation developing during rolling should be $(112)[110, \ldots, 311]$, if only the $\left\{\begin{array}{lll}1 & 1 & 0\end{array}\right\}\left\langle\begin{array}{llll}1 & 1 & 1\rangle\end{array}\right\rangle$ slip systems are active, or $\left(\begin{array}{llll}1 & 1 & 1\end{array}\right)\left[\begin{array}{lll}1 & 1 & 0, \ldots\end{array}\right.$ 211 , if only the $\left\{\begin{array}{lll}1 & 1 & 2\end{array}\right\}\left\langle\begin{array}{lll}1 & 1 & 1\rangle\end{array}\right\rangle$ slip systems are active. From these considerations, the experimental results in this study may be interpreted such that the $\left\{\begin{array}{lll}1 & 1 & 2\end{array}\right\}\left\langle\begin{array}{lll}1 & 1 & 1\end{array}\right\rangle$ slip systems are more active at higher temperatures. A more detailed analysis of the presented results can be achieved by application of a Taylor-type deformation simulation as has been done in an earlier study by Raabe [5]. Currently such simulation using different fraction of $\left\{\begin{array}{lll}1 & 1 & 2\end{array}\right\}$ and $\left\{\begin{array}{lll}1 & 1 & 0\end{array}\right\}$ slip systems - are on the way. 


\section{Concluding remarks}

Texture measurements were carried out on a $\mathrm{Fe}-26 \mathrm{Al}-5 \mathrm{Cr}$ alloy that was warm rolled at precisely controlled temperatures above and below the stress anomaly temperature and the following results were obtained:

1. The starting material was not completely recrystallised although it was produced by hot rolling at $800{ }^{\circ} \mathrm{C} / 82 \%$ followed by the heat treatment at $1000^{\circ} \mathrm{C}$ for $20 \mathrm{~h}$.

2. The warm rolling texture evolution should be measured by the EBSD which allows separation of the originally recrystallised and unrecrystallised areas in this material. Only those areas were considered for further analysis which were recrystallised in the starting material.

3. Recrystallisation does not occur during rolling at 400 and $600{ }^{\circ} \mathrm{C}$ to a reduction of $70 \%$. On the other hand, dynamic and/or static recrystallisation occurs after $\sim 40 \%$ reduction at $700^{\circ} \mathrm{C}$.

4. A clear difference in rolling texture evolution appeared above and below the stress anomaly temperature; the most preferred orientations after rolling at 600 and $400^{\circ} \mathrm{C}$ are $\sim\{557\}\langle 110\rangle$ and $\sim\{111\}\langle 211\rangle$, respectively. This result suggests that the shear fraction of the $\left\{\begin{array}{lll}1 & 1 & 2\end{array}\right\}\left\langle\begin{array}{llll}1 & 1 & 1\rangle & \end{array}\right.$ slip systems increases with respect to that of the $\{110\}\langle 111\rangle$ slip systems with increasing temperature around the stress anomaly temperature.

\section{Acknowledgements}

Authors would like to thank Mr. U. Tezins and Dr. W. Rasp of the Max Planck Institute for Iron Research for the help in the rolling experiments.

\section{References}

[1] D.G. Morris, M.A. Morris, Mater. Sci. Eng. A 239/240 (1997) 23.

[2] N.S. Stoloff, Mater. Sci. Eng. A 258 (1998) 1.

[3] F. Stein, A. Schneider, G. Frommeyer, Intermetallics 11 (2003) 71

[4] B.K. Kad, J.A. Horton, Mater. Sci. Eng. A 239/240 (1997) 118.

[5] D. Raabe, Acta Mater. 44 (1996) 937.

[6] D. Raabe, Steel Res. 66 (5) (1995) 222.

[7] D. Raabe, Z. Zhao, S.-J. Park, F. Roters, Acta Mater. 50 (2002) 421.

[8] D. Raabe, J. Keichel, Mater. Sci. Eng. A 203 (1995) 208.

[9] E.A. Calnan, C.J.B. Clews, Phil. Mag. 42 (1951) 616. 